\title{
ESPACIOS URBANOS EN EL TEATRO ESPAÑOL DE LOS SIGLOS XX Y XXI
}

\author{
Cerstin BAUER-FUNKE (ed.)
}

(Hildesheim/Zürich/New York: Georg Olms, 2016, 472 págs.)

Como broche de oro del coloquio internacional de junio de 2014 llevado a cabo en la Westfálische Wilhelms-Universität Münster, este tomo recoge los estudios de críticos reconocidos, además de las ponencias de los cuatro dramaturgos invitados y una pieza breve de cada uno: Jesús Campos García, Carmen Resino, José Manuel Corredoira Viñuela y Diana M. de Paco Serrano. Los estudios se acercan a varios otros autores también, desde perspectivas distintas, aunque varios siguen un hilo en común. Al final del tomo hay pequeñas biografías de cada contribuidor. La comprensiva introducción de la organizadora del coloquio y editora del tomo, Cerstin Bauer-Funke, plantea la definición de lo urbano (tanto la red de espacios urbanos como los seres que los habitan) y resume rápidamente los 26 ensayos críticos. Al leer su introducción perspicaz, los lectores ya tienen la esencia de los estudios, los cuales indagan en cada aspecto del espacio urbano en el teatro: escenografía y referencias verbales que establecen lugar, dicotomías entre la realidad del espacio fuera de escena y el ficticio del representado, espacios teatrales en sí, utopías y distopías y el no-lugar de Marc Augé, espacios que resultan cada vez más negativos en nuestra sociedad.

Jesús Campos García destaca la importancia histórica del teatro en el desarrollo de la identidad. Al compartir la memoria, la humanidad avanza la historia cuando logra convertir su beligerancia en convivencia y 
socialización. La ficción dramática es memoria elaborada, representando en escena los problemas que la sociedad necesita resolver. Campos García repasa su propia historia de dramaturgo, subrayando sus estrategias para poner en escena espacios contemporáneos incluso en obras históricas. El dramaturgo José Manuel Corredoira Viñuela discute lo urbano en su propio teatro, destacando su aspecto antiutópico. Describe sus obras como multilingüe y multigenérico, usando Cacotopía como un espacio a la vez de Paraíso y de Infierno.

Carmen Resino reflexiona sobre los espacios claustrofóbicos, a puerta cerrada, en el teatro español de los siglos XX y XXI, y sobre su propio teatro, de incomunicación y soledad. Cita a Benavente y su teatro rural, luego a Sartre, como marcadores del tema.

Diana M. de Paco Serrano discute como, en sus obras, la sociedad es la amenaza contra la que sus personajes buscan protegerse; su meta es de romper la soledad urbana mediante el teatro mismo. Repasa los espacios --cerrados, por lo general-- de su propio teatro, analizando en detalle Espérame en el cielo...o, mejor, no.

Otros ensayos se agrupan según su acercamiento, muchos centrándose en Madrid. José María Paz Gago indica que la ciudad de Luces de bohemia contiene referencias realistas pero no fácticas y que los espacios de Ramón del Valle-Inclán tienen vigencia a través de los lugares de manifestaciones y detenciones actuales. Víctor García Ruiz repasa las etapas de construcción de Madrid y cómo afectaron tanto la identidad de la ciudad como la de Víctor Ruiz Iriarte, dando ejemplos de su teatro. Cerstin Bauer-Funke analiza las dicotomías visuales y simbólicas en el teatro de la Generación Realista, proporcionando un estudio riguroso de su uso de contrastes entre lo cerrado y lo abierto en cuanto a la estructuración de las obras y su decorado en cinco autores. La bibliografía de este estudio es impresionante. Carmen Rivero examina cómo Antonio Buero Vallejo utiliza el espacio irreal de la utopía para analizar el espíritu geométrico de Esquilache en Un soñador para un pueblo. Hay un cambio a México con el ensayo de Manuel Aznar Soler, quien estudia Plaza de las Tres Culturas. Tlatelolco, de Juan Miguel de Mora y cómo la plaza sirve de espacio real de memoria, combinando hechos históricos de siglos distintos.

Volviendo a Madrid, Antonia Amo Sánchez examina cómo el papel de la ciudad en las obras de José Luis Alonso de Santos ha cambiado: el espacio utópico desaparece, dando lugar al infra-lugar de espacio urbano 
donde se reúnen los excluidos de la sociedad. El espacio urbano nocturno es el tema del análisis de Mariano de Paco de Noches de amor efímero, de Paloma Pedrero. Discute montajes de las tres obras como conjunto, el cual muestra la totalidad de la ciudad: subsuelo (metro), suelo (parque) y cielo (ático), en un estudio astuto. El metro surge otra vez en el ensayo de Polly J. Hodge, que estudia tres obras recientes; incluye fotos de representaciones y utiliza la teoría de Nikos Salingaros de la estructura urbana como nodos de actividad humana, interconectados por sistemas como el metro. Berta Muñoz Cáliz ofrece un repaso histórico y comprensivo en su estudio virtuoso del Madrid imaginario como espacio teatral desde el Siglo de Oro. Se recalca el fracaso hoy en día de las utopías y cómo Madrid, igual que cualquiera ciudad grande, encarna grandes desigualdades y el maltrato de los desechados. Su análisis detallado de veinte obras teatrales del siglo XXI no deja lugar a dudas sobre la validez de su hipótesis.

Los personajes, sus actitudes y la estructura posmoderna forman el hilo en común entre el análisis de John P. Gabriele de flânerie, badauderie en Ciudad lineal y el de Carole Egger, sobre Metropolitano. Gabriele destaca la alienación urbana representada en Itziar Pascual; Egger examina la negación del paso del tiempo mediante parataxis y asíndeton en Borja Ortiz de Gondra. La alienación posmoderna continúa en el estudio de Virtudes Serrano de los efectos negativos de las calles urbanas que generan marginalidad y exclusión social. Muestra los efectos en Eloídes (Jerónimo López Mozo), Obsession Street (Diana de Paco), y Caídos del cielo (Pedrero), pero en este último destaca la ciudad como espacio de esperanza y regeneración gracias al teatro.

Mónica Molanes Rial presenta la función del mapa en obras de Juan Mayorga, y cómo representa el pasado en el presente, formando la ciudad y su doble, una ciudad invisible y paralela. Lourdes Bueno estudia el topos casa/cuerpo y cómo los interiores escénicos de varios dramaturgos reflejan las emociones, la personalidad y lo más íntimo de los protagonistas. La soledad como centro del análisis se encuentra en el estudio de coches en Javier Magua y Fulgencio M. Lax (con referencias a Arrabal, Caballero y Belbel) de Isabelle Reck, quien recalca el oxímoron de este símbolo de progreso y movimiento sirviendo de símbolo de ruina, inmovilidad y animalización del ser humano en distopías. La búsqueda de utopía que resulta en distopía es tema de discusión en varios estudios más, incluyendo el de Francisco Gutiérrez Carbajo, que extiende su análisis rigurosa de 
más de quince piezas españolas para incluir los paralelos internacionales (Hemingway, Arnold Wesker) e históricos (Lope de Rueda, Valle-Inclán) y hacer referencia a la concepción de Gilles Deleuze de que con la utopía, la filosofía se vuelve política. Eduardo Pérez-Rasilla sondea el espacio de distopías futuras en Flechas del ángel del olvido (José Sanchis Sinisterra) y La selva es joven y está llena de vida (Rodrigo García), subrayando el juego de planos entre presente y futuro para crear espacios reconocibles pero extraños.

Un acercamiento innovador es el uso de la teoría del antropólogo Marc Augé de los no-lugares, utilizado tanto por Wilfried Floeck para examinar los dramas de la inmigración, como por Martin Baxmeyer, para estudiar el movimiento sin comunicación verdadera en los lugares de tránsito. La falta de identidad y la soledad reinan en estos espacios. En los estudios de Cristina Oñoro Otero, Monique Martínez Thomas y José Antonio Pérez Bowie, se examinan técnicas renovadoras. En Oñoro Otero son las salas independientes madrileñas, teatro inmersivo, hiperrealista e ilusionista y las protestas en las calles que utilizan elementos teatrales. Martínez Thomas aplica la teoría de Michel Foucault de la ciudad como dispositivo al colectivo Kamchàtka de Barcelona, concluyendo que su teatro funciona como contra-dispositivo. Pérez Bowie analiza la interinfluencia teatrocine con pantallas en escena y la teatralidad posmoderna apuntada contra los medios de comunicación de masas.

Un aspecto notable de este tomo es la inclusión de las cuatro obras teatrales nuevas de los dramaturgos invitados al coloquio. Campos García se mete con uno de los temas predilectos del coloquio en su pieza $E l$ nolugar, obra que hace uso exitoso del humor y la metateatralidad. ¡Ya! No estamos solos de Resino aborda el problema actual de la incomunicación, con una pareja demasiado ocupada con el móvil para conversar. La pieza de Corredoira se auto-titula "poema representable"; se llama Pan y consiste en dos frases repetidas con matices musicales. De Paco Serrano hace uso de toques de humor negro en Morir de amor. La narración tiene lugar en un no-lugar: el avión y un hotel. Consiste en el monólogo de una mujer ya madura que se alegra de su liberación amorosa, con un final de sorpresa.

Para los estudiosos del teatro español contemporáneo, esta colección de ensayos analíticos es imprescindible. Con la adición de las cuatro piezas nuevas de dramaturgos reconocidos, el libro debe interesar a un público más general a la vez que uno especialista. 
Eileen J. Doll

Loyola University New Orleans 
